\title{
A GESTÃO DE RELACIONAMENTO COM CLIENTES (CRM) COMO UM IMPORTANTE RECURSO PARA O CRESCIMENTO EMPRESARIAL
}

\author{
CUSTOMER RELATIONSHIP MANAGEMENT (CRM) AS AN IMPORTANT \\ RESOURCE FOR BUSINESS GROWTH
}

\begin{abstract}
Thais Miria dos Santos - miriathais98@gmail.com
Gustavo Henrique Del Vechio - gustavo.vechio@fatecbb.edu.br

Faculdade de Tecnologia de Bebedouro (Fatec) - Bebedouro - São Paulo - Brasil
\end{abstract}

DOI: 10.31510/infa.v17i1.780

\begin{abstract}
RESUMO
Houve um tempo em que as estratégias de marketing empresariais concentravam seu foco exclusivamente nos produtos e em como vendê-los. No entanto, ao longo do tempo, percebeuse que o foco do marketing deveria ser deslocado dos produtos aos clientes e em como manter um bom relacionamento com eles. Posto dessa forma, este estudo procura analisar a importância da gestão de relacionamento com os clientes (CRM), tendo em vista que este é um conceito muito importante para as empresas manterem um vínculo mais duradouro com seus públicos de interesse. É o caso de uma grande cooperativa agrícola do interior de São Paulo, mencionada como estudo de caso neste trabalho, que tem crescido cada vez mais com a ajuda de ferramentas e recursos CRM. O que se verifica, por este estudo, é que quanto mais as empresas ouvirem, compreenderem e colocarem os clientes no centro de suas estratégias, mais chances tem de crescer e ganhar posição de destaque no mercado.
\end{abstract}

Palavras-chave: Gestão de Relacionamento com o Cliente (CRM). Marketing. Relacionamento. Crescimento empresarial.

\begin{abstract}
There was a time when business marketing strategies focused exclusively on products and how to sell them. However, over time, it was realized that the focus of marketing should shift from products to customers and on how to maintain a good relationship with them. Put this way, this study seeks to analyze the importance of customer relationship management (CRM), considering that this is a very important concept for companies to maintain a more lasting bond with their stakeholders. This is the case of a large agricultural cooperative in the interior of São Paulo, mentioned as a case study in this work, which has grown more and more with the help of CRM tools and resources. What we see from this study is that the more companies listen, understand and put customers at the center of their strategies, the more chances they have of growing and gaining a prominent position in the market.
\end{abstract}

Keywords: Customer Relationship Management (CRM). Marketing. Relationship. Business growth. 


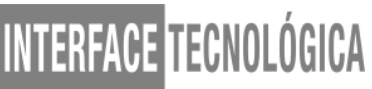

\section{INTRODUÇÃO}

Este estudo tem o objetivo de compreender a Gestão de Relacionamento com o Cliente, do inglês "Customer Relationship Management" (CRM), não exatamente como um recurso tecnológico (isto é, como um conjunto de ferramentas ou softwares), mas sim como um conceito abrangente e cada vez mais relevante para as empresas estreitarem o relacionamento com seus clientes e manter, assim, um vínculo mais duradouro com eles.

Para alcançar este objetivo, a metodologia do estudo se define, primeiramente, pela revisão de livros, revistas e matérias especializadas, a fim de compreender as bases da Gestão de Relacionamento com o Cliente, ferramentas disponíveis e, de maneira geral, suas implicações no marketing empresarial (isto é, nas estratégias de negócio). Em seguida, o trabalho apresenta um estudo de caso em que ferramentas CRM foram implementadas em uma grande cooperativa agrícola do interior de São Paulo, a fim de potencializar seu crescimento e assegurar um relacionamento mais próximo junto a seus milhares de cooperados.

O estudo se justifica por verificar que, cada vez mais, os clientes devem estar no centro das estratégias de negócio. Quanto mais as empresas entenderem, ouvirem e se relacionarem bem com seus diferentes públicos, mais chances têm de crescer e se destacar.

\section{FUNDAMENTAÇÃO TEÓRICA}

\subsection{Marketing e a gestão de clientes}

Se uma empresa tinha uma ideia inovadora por volta de 1950 ou 1960, demoraria um certo tempo até os concorrentes lançarem produtos equivalentes ou com atrativos melhores. Logo, era natural que as estratégias de marketing, que começavam a ser estudadas na época, voltassem seu foco exclusivamente nos produtos. Prova disso é o famoso conceito dos 4 Ps (produto, preço, praça e promoção) consolidado por Jerome McCarthy no início da década de 1960 e que permaneceu, por muitos anos, como a sustentação das estratégias de mercado para as empresas: "todas as organizações empresariais, tendo ou não fins lucrativos, encontrariam nos 4 Pês de McCarthy sua base de interação com o mercado" (YANAZE, 2011, p. 33).

Nestas épocas, a função principal do marketing, embasada pelas variáveis dos 4 Ps, tal como complementam Kotler, Kartajaya e Setiawan (2010, p. 30), era de gerar demanda de 
produtos. Ou seja, pensava-se em como desenvolver bons produtos, seus formatos, características, modelos e variáveis ( $\mathrm{p}$ - produto), como precificar, adotar políticas de desconto e promoção de vendas ( $\mathrm{p}$ - preço), como distribuí-los, estoca-los e em quais pontos de venda disponibilizá-los ( $\mathrm{p}$ - praça), bem como a melhor maneira de divulga-los e torna-los conhecidos por parte do público ( $\mathrm{p}$ - promoção). O foco, definitivamente, estava no produto em si.

No entanto, com as evoluções tecnológicas em diversas áreas, o crescimento da concorrência e o acesso à informação, além de crises e incertezas econômicas, o cenário de mercado mudou. Notou-se que, no modelo dos 4 Ps, faltava um importante elemento ainda deixado em segundo plano: os próprios clientes e seus desejos. Kotler, Kartajaya e Setiawan (2010, p. 29) explicam, então, que muitas empresas, por volta da década de 1970, logo perceberam que o foco das estratégias de negócio deveria ser deslocado do produto para os próprios consumidores. Assim, como acrescenta Del Vechio:

\footnotetext{
...mais do que apresentar e vender excelente produtos (como se isso bastasse), as marcas compreenderam a importância de pôr os clientes no centro de suas estratégias, procurando estabelecer um vínculo em que ambos pudessem dialogar e consolidar um relacionamento mais longínquo (DEL VECHIO, 2018, p. 263).
}

Ou seja, para gerar demanda, os consumidores e seus desejos deveriam se integrar à gestão de produtos, a fim de atualizar o modelo estrutural dos 4 Ps. Foi nessa época que o marketing evoluiu de tático para tornar-se estratégico, introduzindo conceitos como segmentação e definição de mercado, posicionamento de marca, além de criar mecanismos para gerir o relacionamento com o cliente (tendo em vista, afinal, que a venda não é o único propósito do negócio). É justamente deste cenário que surge o conceito de "Gestão de Relacionamento com o Cliente", em inglês “Customer Relationship Management" ou, simplesmente, CRM.

Hoje, as marcas que não compreenderem bem seus clientes podem pagar um preço alto demais em relação à sua participação no mercado (REICHHELD; MARKEY, 2011, p. 21-27). Colocar produtos no mercado não é suficiente; é preciso se conectar aos consumidores e manter uma relação estreita de confiança com eles. Afinal, com tantos produtos sendo lançados frequentemente no mercado, ninguém pode esperar que um consumidor continue a adquirir produtos ou serviços de marcas que simplesmente não os conhecem, entendem ou se preocupam com eles. Como escrevem Kotler e Keller (2012, p. 134-148), ser capaz de gerar uma forte conexão com clientes é o sonho de qualquer empresa e, a longo prazo, a chave do sucesso para os negócios. 


\subsection{Definição de CRM}

O CRM, portanto, corresponde aos esforços da empresa em se relacionar e manter um vínculo mais ativo e duradouro com os clientes, tendo em vista as áreas de atuação, produtos e serviços oferecidos pela empresa. Como complementam Swift (2001, p. 25) e Zenone, (2007, p.14), este é, definitivamente, um valioso recurso para o sucesso empresarial.

Logo, é importante destacar, como explicam Garrafoni Júnior et. al (2006, p. 15), que o CRM não deve ser entendido tão somente como um aplicativo e tampouco deve ser considerado um esforço exclusivo do departamento de marketing da empresa. Pelo contrário, o CRM é um conceito amplo, que deve ser compreendido e exercido diariamente por diversos departamentos e profissionais envolvidos no negócio. Ou seja, trata-se de um conjunto de estratégias, práticas e políticas de gestão e conexão com o público, com o objetivo não apenas de satisfazê-lo, mas de se manter em contato e próximo a ele.

\subsection{Desafios e benefícios do CRM}

Swift (2001, p. 24) argumenta que existem dois principais benefícios quanto à aplicação de técnicas e uso de aplicativos CRM dentro da empresa: em primeiro lugar, eles podem segmentar melhor o público e direcionar produtos e serviços específicos a cada cliente; em decorrência disso, em segundo lugar, encontram-se as melhorias relacionadas aos custos e direcionamento do orçamento empresarial. Não é surpresa, neste sentido, Garrafoni Júnior et al. (2006, p. 26) argumentarem que as empresas que adotam o CRM melhoram sua estratégia competitiva, justamente por voltarem sua atenção ao bom relacionamento com os clientes.

Mazza (2009, p. 6), entretanto, alerta para o fato de que a implantação do CRM requer diversos esforços organizacionais, já que é preciso que gestores, funcionários e colaboradores compreendam os conceitos e os apliquem de acordo com cada situação de negócio. Ou seja, o CRM requer um esforço coletivo em que os diferentes departamentos da empresa devem trabalhar em conjunto, sempre em busca de manter o relacionamento com o público.

Posto dessa forma, para Wildner (2016, p. 12), é muito importante que o sistema CRM adotado pela empresa seja alimentado com informações atualizadas quanto às características, comportamento e desejos dos consumidores. Tal coleta de dados, que pode ser realizada de diversas maneiras, tais como por observação empírica, questionários de pesquisa, intervenções 
em redes sociais e outros, podem ajudar consideravelmente a traçar o perfil de cada tipo de público, a fim de se conectar com ele de maneira mais exclusiva, particular e efetiva. Greenberg (s.d., p. 2) complementa: "é preciso resistir à comodidade do distanciamento e entender toda e qualquer informação sempre sob a perspectiva do cliente."

\subsection{Tecnologias CRM e aplicativos}

A base da gestão do relacionamento com o cliente está no uso de aplicativos, capazes de cruzar e analisar dados, bem como traçar perfis e suas particularidades. Azevedo et al. (2006, p. 182-183) esclarecem que as funcionalidades do CRM são divididas em três, sendo operacional, analítica e colaborativo. Cada uma destas funcionalidades tem o objetivo de coletar informações e, assim, aproximar o consumidor da empresa.

Mais especificamente, as funcionalidades operacionais são as que integram vários canais de contatos, a fim de aproximar empresa e consumidores (um exemplo clássico são os call centers). Já as funcionalidades analíticas são as que identificam e acompanham as ações dos mais variados tipos de público, permitindo, em seguida, elaborar um plano estratégico para atender as necessidades específicas de cada consumidor. Por fim, as funcionalidades colaborativas são as que dão suporte à empresa e proporcionam a integração dos pontos de contato com os consumidores, possibilitando a troca de informações de forma eficaz e direta.

Kaplan e Blanco (2018, p. 5) apresentam uma interessante tabela em que pode ser observado com mais facilidade as vantagens e desvantagens ao utilizar aplicativos CRM:

Tabela 1 - Tabela comparativa quanto às vantagens e desvantagens de aplicativos CRM.

\begin{tabular}{|c|c|c|}
\hline & VANTAGENS & DESVANTAGENS \\
\hline $\begin{array}{l}\text { Estratégia } \\
\text { manual }\end{array}$ & $\begin{array}{l}\text { Permite liberar informações necessárias } \\
\text { sobre as necessidades de clientes atuais e } \\
\text { potenciais; permite saber e detalhar } \\
\text { mudanças e preferências do cliente em certos } \\
\text { produtos e serviços; permite detectar } \\
\text { sensações e expectativas pessoais de clientes } \\
\text { antes e depois de consumir os produtos. }\end{array}$ & $\begin{array}{l}\text { O processamento da informação é lento, } \\
\text { o que pode trazer informações erradas. }\end{array}$ \\
\hline
\end{tabular}




\begin{tabular}{|l|l|l|}
\hline Estratégia & Permite processar as informações muito mais & Nem todos os requisitos dos clientes \\
com & rápido; pode tomar decisões oportunas em & podem ser processados; tem que ser \\
software & pouco tempo; permite aproveitar certas & levado em consideração o custo de um \\
CRM & $\begin{array}{l}\text { oportunidades comerciais que são dadas em } \\
\text { determinados momentos do mercado; pode } \\
\end{array}$ & software. \\
& $\begin{array}{l}\text { ter um maior escopo para o seu estudo com } \\
\text { grande número de clientes processados. }\end{array}$ & \\
& & \\
& & \\
\end{tabular}

Fonte: adaptado e traduzido de Kaplan e Blanco (2018, p. 5).

Ao realizar uma pesquisa de mercado, pode-se notar a existência de diversos aplicativos que podem ser utilizados como sistema CRM. Alguns deles incluem:

- Salesforce: destaca-se pelas facilidades em encontrar os melhores clientes em potencial (que possuem interesse em adquirir o produto ou serviço oferecido), além de entrar em contato com eles de forma rápida e eficaz.

- Microsoft CRM: destaca-se pela compatibilidade com a linha de aplicativos da Microsoft, oferecendo, por exemplo, integração com pacote Office.

- Oracle: destaca-se pelo foco nas redes sociais, o que facilita a comunicação com os consumidores, independente de ligações telefônicas ou e-mails.

- Sugar CRM: é caracterizado por sua baixa complexidade, podendo oferecer amplo suporte aos profissionais que nunca utilizaram esse tipo de sistema.

- Clover CRM: é um aplicativo mais voltado para o agronegócio, sendo capaz de mapear dados por meio de uma sólida base de dados, além de segmentar os produtores por suas produções em potencial. 


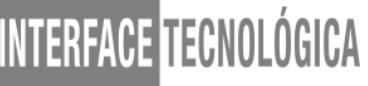

Como é possível verificar, há diversas opções disponíveis, cada qual específica a certas aplicações e ramos de negócio. Todas, entretanto, destinam-se a um objetivo primário: melhorar ou estreitar a conexão entre a empresa e seus públicos de interesse.

\section{PROCEDIMENTOS METODOLÓGICOS}

A fim de corroborar os conceitos apresentados e demonstrar os benefícios do CRM em favor de uma empresa, apresenta-se, a seguir, um estudo de caso em que ferramentas CRM são aplicadas na prática, a fim de garantir à uma grande cooperativa do interior de São Paulo mais eficiência em seus serviços e na conexão com seus públicos de interesse.

Esta cooperativa, por ter a necessidade de manter uma estreita integração entre as áreas de venda e logística (seus principais serviços), procurou nos recursos CRM (que já foram descritos nas páginas anteriores), ampliar a taxa de sucesso em suas operações.

O desejo, por parte da cooperativa, em contratar um aplicativo para mapeamento do seu público (vide lista com exemplos de aplicativos no item 2.4 do estudo), surgiu da premissa de que a tecnologia poderia facilitar o oferecimento de serviços direcionados a cada indivíduo (neste caso, os cooperados), dentro da área em que atua, que é o agronegócio. Mais especificamente, o objetivo foi difundir o atendimento nas propriedades agrícolas, a partir de um sistema capaz de mostrar a vendedores ou representantes comerciais o tipo exato de cultura de cada propriedade, a fim de separar, por região, os principais cooperados e seus interesses. Esta é uma perspectiva muito interessante, afinal, como demonstram Kotler e Keller (2012, p. 228-256) tanto quanto Yanaze (2011, p. 185-222), quanto mais as empresas se preocuparem em entender seu público, segmenta-lo e oferecer soluções específicas a eles, mais chances tem de ganhar mercado e manter a confiabilidade e o vínculo com seu público (este é o desafio da gestão de relacionamento com o cliente).

Posto dessa forma, a empresa contratou, em 2018, o sistema CRM chamado Clover, que é desenvolvido pela Datacoper (vide www.datacoper.com.br/produtos/clover-crm) e tem seu foco justamente em negócios especializados na venda de insumos e produtos agrícolas.

O Clover CRM possibilitou o mapeamento de cooperados por região, área de atuação e cultura plantada. Tais informações foram extremamente importantes para a divisão logística da empresa, pois permitiu a ela elaborar melhores roteiros de viagem, obter economia em combustível e hospedagem, além de isentar a cooperativa de acrescentar o valor destas despesas 


\section{WWTEPFAG TEECNOLOGGCA}

no preço a ser repassado para os consumidores. Outras vantagens ainda incluíram evitar viagens desnecessárias, monitor melhor o tempo de entrega de produtos e o controle do nível de serviços, entre outros indicadores relevantes para o sucesso nas operações da cooperativa.

\section{RESULTADOS E DISCUSSÃO}

Com a utilização do Clover CRM, a cooperativa pode expandir sua área de atuação, aumentar algumas filiais e, aliás, aumentar sua receita e patrimônio líquidos, o que combina com os benefícios descritos por Swift (2001), Mazza (2009) e Wildner (2016), abordados no item 2.3 deste estudo. Mais especificamente, a área de atuação da cooperativa, até 2017 (antes da implementação do CRM), era restrita a dois estados, São Paulo e Minas Gerais, sem grande dispersão de filiais: eram 133; no final de 2019, quase 3 anos após o uso de recursos CRM, a quantidade de filais saltou para 170, o que proporcionou ocupação maior nos dois respectivos estados, além da expansão para o estado de Goiás (COOPERCITRUS, 2020). A participação das ferramentas CRM neste processo se deu justamente por realizar e proporcionar uma análise mais rigorosa quanto aos melhores locais ou regiões para a abertura de novas filiais; já o mapeamento de culturas agrícolas em cada região, como por exemplo café, grãos (soja, milho), cana de açúcar, culturas de hortifruti (frutas, verduras e legumes), possibilitou à cooperativa decidir com mais certeza os principais locais a explorar nos estados brasileiros de seu interesse. Esta é uma perspectiva que Wildner (2016) defende como sendo importantíssima aos negócios.

Tal sucesso na expansão empresarial pode ser verificado, inclusive, nos balanços patrimoniais públicos, que demonstram claramente um aumento expressivo em sua receita líquida anual: se em 2017 a cooperativa fechou o ano com sua receita líquida em 2.8 bilhões de reais, no ano de 2018, quando o CRM foi implementado, a receita líquida saltou e fechou o ano em 3.69 bilhões, ou seja, um aumento de $29.66 \%$ em relação ao ano anterior. No ano de 2019 , o fechamento foi de 4.567 bilhões, o que representa um aumento de $16.15 \%$ em relação à 2018 (COOPERCITRUS, 2020). Percebe-se, por estes valores, o quanto a cooperativa têm crescido anualmente, neste caso tendo o suporte de recursos CRM. Aliás, a própria Datacoper, fabricante do software Clover CRM, fez um vídeo demonstrando o impacto positivo que esta ferramenta teve nos negócios da cooperativa. Ele pode ser assistido pelo link https://bit.ly/39SDIs1. 


\section{CONSIDERAÇÕES FINAIS}

Desde que o marketing percebeu a importância de se colocar os clientes no centro das estratégias de negócio, a "Gestão de Relacionamento com o Cliente" (CRM) tornou-se um conceito cada vez mais essencial para as empresas compreenderem seus clientes e estreitarem o relacionamento com eles. Hoje, as empresas que não forem capazes de segmentar, entender e ouvir seus diferentes públicos, podem pagar um preço muito alto em relação à sua posição ou permanência no mercado.

Há, atualmente, diversos recursos e softwares especializados em oferecer mais suporte à gestão de relacionamento com o cliente, no entanto, como este estudo procurou demonstrar, o CRM vai muito além da esfera tecnológica, pois deve ser entendido como um conceito a ser reforçado e seguido por todos aqueles que fazem parte do negócio. É assim que a empresa pode, enfim, estreitar o relacionamento com os clientes e gerar um vínculo mais duradouro com eles.

Como exemplo, o artigo citou o caso da Coopercitrus, cooperativa agrícola do interior de São Paulo, que recentemente investiu em uma plataforma CRM para compreender melhor quem são seus cooperados e, com isso, não apenas conhece-los melhor, mas também otimizar suas operações logísticas e de marketing como um todo. Os relatórios anuais da cooperativa deixam claro o aumento nas filiais e em receita líquida, cujo sucesso certamente tem o apoio desta nova etapa de negócios, a partir do uso dos recursos CRM. É, afinal, uma prova concreta de que investir no relacionamento com clientes e conhecê-los melhor só tende a gerar bons frutos e crescimento empresarial.

\section{REFERÊNCIAS}

AZEVEDO, Rodrigo C.; BREMER, Carlos F.; REBELATTO, Daisy A. N.; TARALLO, Felipe $\mathrm{B}$. O uso de ERP e CRM no suporte à gestão da demanda em ambientes de produção Make-to-Stock. Revista Gestão e Produção, 2006, vol. 13, n. 2. Disponível em: < https://bit.ly/39OuixC >. Acesso em: 7 fev. 2020.

COOPERCITRUS. Relatório de Gestão 2019. Coopercitrus, 2020. Disponível em: < http://www.coopercitrus.com.br/upload/balancos/26.pdf >. Acesso em: 6 abr. 2020.

DEL VECHIO, Gustavo H. Conexão emocional entre marcas e clientes: análise de confiabilidade no mercado comercial. 2018. 375f. Tese de Doutorado em Comunicação Social: Universidade Metodista de São Paulo, São Bernardo do Campo, 2018. 
GARRAFONI JÚNIOR, Atílio; SANTADE, Hélio O.; PIZZINATTO, Nadia K.; FARAH, Osvaldo E. CRM: conceitos e métodos de aplicação no marketing de relacionamento. Revista Gestão Industrial, vol. 1, n. 3, 2006. Disponível em: < https://bit.ly/34kXRpr $>$. Acesso em: 6 fev. 2020.

GREENBERG, Paul. CRM na velocidade da luz. HSM Management, s.d. Disponível em: < http://usuarios.upf.br/ ricardo/CRM.pdf >. Acesso em: 19 mar. 2020.

KAPLAN, Gladys N.; BLANCO, Gabriel E. Implementaciones de softwares CRM. Revista Digital del Departamento de Ingeniería e Investigaciones Tecnológicas de la Universidad Nacional de La Matanza, vol 3, n. 1, jul. 2018. Disponível em: < https://bit.ly/2yL4p53 >. Acesso em: 27 fev. 2020.

KOTLER, Philip; KARTAJAYA, Hermawan; SETIAWAN, Iwan. Marketing 3.0: as forças que estão definindo o novo marketing centrado no ser humano. Rio de Janeiro: Elsevier, 2010 .

KOTLER, Philip; KELLER, Kevin L. Administração de Marketing. 14 ed. São Paulo: Prentice Hall, 2012.

MAZZA, Marcos F. CRM: sucessos \& insucessos. Rio de Janeiro: Brasport, 2009.

REICHHELD, Frederick F.; MARKEY, Rob. The ultimate question 2.0: how net promoters companies thrive in a customer-driven world. 2 ed. Boston: Harvard Business School, 2011.

SWIFT, Ronald. CRM - Customer Relationship Management: o revolucionário marketing de relacionamento com os clientes. 13 ed. Rio de Janeiro: Elsevier, 2001.

WILDNER, Gregory P. Implantação da estratégia de CRM em uma igreja. Trabalho de Conclusão de Curso. Graduação em Administração. Universidade Federal de Fronteira do Sul - UFFS, Chapecó, 2016. Disponível em: < https://bit.ly/2URyYhW >. Acesso em: 12 mar. 2020.

YANAZE, Mitsuru H. Gestão de Marketing e Comunicação: avanços e aplicações. 2 ed. São Paulo: Saraiva, 2011.

ZENONE, Luiz C. CRM - Customer Relationship Management: gestão de relacionamento com o cliente e a competitividade industrial. São Paulo: Novotec, 2007. 